\title{
Aromatic nitrations by mixed acid. Fast liquid-liquid reaction regime
}

\author{
J.M. Zaldívara , E. Molga ${ }^{\mathrm{b}}$, M.A. Alós ${ }^{\mathrm{a}}$, H. Hernández ${ }^{\mathrm{a}}$, K.R. Westerterp ${ }^{\mathrm{c}}$ \\ ${ }^{a} J o i n t$ Research Centre of the Commission of the European Communities, Institute for Safety Technology, Process Engineering Division TP680, \\ 21020-Ispra (Va), Italy \\ ${ }^{\mathrm{b} C h e m i c a l}$ Engineering and Process Department, Warsaw Technical University, ul. Warynskiego 1, 00645-Warsaw, Poland \\ ${ }^{c}$ Chemical Reaction Engineering Laboratories, Department of Chemical Engineering, Twente University of Technology, P.O. Box 217, \\ 7500 AE Enschede, Netherlands \\ Received 10 February 1995; accepted 8 May 1995
}

\begin{abstract}
Aromatic nitration by mixed acid was selected as a specific case of heterogeneous liquid-liquid reaction. An extensive experimental programme was followed using adiabatic and heat flow calorimetry and pilot reactor experiments, supported by chemical analysis. A series of nitration experiments was carried out to study the influence of different initial and operating conditions, such as temperature, stirring speed, feed rate and sulphuric acid concentration. In parallel, a mathematical model to predict the overall conversion rate was developed. In this paper, the mathematical modelling, implementation and experimental validation for mononitrations of benzene, toluene and chlorobenzene in the mass transfer controlled regime of fast liquid-liquid reactions are presented and discussed.
\end{abstract}

Keywords: Aromatic nitration; Fast liquid-liquid reactions; Heterogeneous dispersions

\section{Introduction}

Despite the fact that aromatic nitration in mixed acid was one of the earliest unit processes to be operated on a large scale (when the heavy organic chemical industry started its development by the end of the last century), many questions remain to be answered, particularly in discontinuous rcactors. The dynamic behaviour of aromatic nitrations in semibatch processes involves a considcrable number of problems, because in these heterogeneous liquid-liquid dispersions chemical reaction and mass transfor phenomena occur simultaneously. Furthermore, as the nitration proceeds, the acid phase composition varies and the observed secondorder rate constant decreases appreciably [1].

In previous work [2], the mechanistic aspects of homogeneous aromatic nitrations were studied to check their validity under heterogeneous conditions and with high nitric acid concentrations. To that end, the slow liquid-liquid reaction regime was chosen. In such a regime, i.e. low sulphuric acid strengths, the rate of mass transfer is not enhanced by reaction and the reactions proceed in the bulk of the reaction phase, not in the boundary layer.

As we increase the sulphuric acid strength, the nitration rate constant increases and the heterogeneous system enters into the fast regime. In this situation, the rate of reaction is affected not only by the physical and chemical characteristics of the system, but also by the mechanical features of the equipment [3]. The former includes the viscosities and densities of the phases, interfacial surface properties, diffusion coefficients, distribution cocfficients of reagents and products between phases and chemical reaction constants. The latter includes, for example, the type and diamcter of the impeller, the vessel geometry, the flow rate of each phase and the rotational speed of the impeller. Furthermore, dispersion phenomena such as the coalescence and breakage of droplets, the drop size distribution and phase inversion phenomena will affect the extent of conversion and the selectivity of the reactions [4].

To take into account such parameters, experiments have been performed to characterize separately their influence, when possible. The interfacial area for our equipment was characterized using a similar non-reactive system [5]. Furthermore, nitration experiments on 
benzene, toluene and chlorobenzene in the fast regime were carried out to compare with the model predictions. The model employed, based on the effective interfacial area between the two liquids and the description of mass transfer with reaction using the film model, is the most common approach. Theoretical model predictions were compared with the experimental results and the effect of the different parameters is discussed. From the comparisons between model and experimental results, it can be concluded that it is possible to extrapolate data from homogeneous nitration experiments to heterogeneous systems and to interpret the dynamic behaviour of discontinuous nitration processes of benzene, toluene and chlorobenzene in different reaction regimes.

\section{Interfacial area measurement and estimation}

The effective interfacial area is an important parameter which determines the efficiency and capacity of agitated liquid-liquid contactors; it is normally evaluated by the expression

$a=\frac{6 \varepsilon_{\mathrm{d}}}{d_{32}}$

where $\varepsilon_{\mathrm{d}}$ is the fraction of the dispersed phase and $d_{32}$ is the Sauter mean diameter which can be computed as

$d_{32}=\frac{\sum_{i} n_{i} d_{i}^{3}}{\sum_{i} n_{i} d_{i}^{2}}$

where $n_{i}$ is the number of droplets with a diameter $d_{i}$. The Sauter mean diameter cannot be evaluated through a simple analysis. Therefore it is customary to evaluate the maximum stable diameter $d_{\max }$ encountered in the impeller zone of the vessel and to multiply it by an empirical factor to obtain $d_{32}$ [6].

A liquid-liquid dispersion formed in an agitated vessel is characterized by a dynamic equilibrium between drop breakup and coalescence. The droplet size distribution and the interfacial area depend on the conditions of agitation and the physical properties of the system. The microscopic phenomena occurring in an agitated vessel are extremely complex. The exact mechanism of coalescence and breakage in systems of droplets is generally not very well understood [7]. Drops are believed to be broken up in regions of high shear stress near the agitator blades or due to turbulent velocity and pressure variations along the surface of a single drop. Coalescence occurs when drops collide and the collision happens to be "efficient", i.e. the amplitude of the fluctuation is high enough to overcome the resistance of the liquid film separating the drops.
A fairly extensive literature exists with regard to the average drop size obtained in dispersions. Semiempirical correlations are based on the local isotropy concept of Kolmogorov [8], who proposed that the breakup of a drop occurs when the ratio of the inertial stress to the stress due to interfacial tension exceeds a critical value. Kolmogorov's [8] expression for $d_{\max }$ is

$\frac{d_{\max }}{D_{\mathrm{a}}}=c_{1} \mathrm{We}^{-0.6}$

where We is the Weber number of the main flow, defined as

$\mathrm{We}=\frac{\rho_{\mathrm{c}} n_{\mathrm{a}}^{2} D_{\mathrm{a}}^{3}}{\sigma}$

This expression cannot be used when the dispersed phase hold-up is larger than 0.05 or when the dispersed phase is viscous, because the deformation rate is neglected. To take into account these restrictions, various expressions to calculate $d_{\max }$ or $d_{32}$ have been proposed $[9,10]$. The general form of the correlations is

$\frac{d_{32}}{D_{\mathrm{a}}}=A \mathrm{f}\left(c_{\mathrm{d}}\right) \mathrm{We}^{-0.6}$

where $f\left(\varepsilon_{\mathrm{d}}\right)$ normally represents a linear correlation of the volume fraction of the dispersed phase

$\mathrm{f}\left(\varepsilon_{\mathrm{d}}\right)=1+B \varepsilon_{\mathrm{d}}$

The constant $B$ in Eq. (6) can vary between 2.0 and 9.0 for dispersions where $\varepsilon_{\mathrm{d}}<0.2$ [10]. In a recent study, Brooks and Richmond [11] showed that correlations of this type will become very inaccurate for $\varepsilon_{\mathrm{d}}>0.3$ and that the theoretical correlation developed by Delichatsios and Probstein [12] should be used instead. In this case, the function of the dispersed phase volumetric fraction $\mathrm{f}\left(\varepsilon_{\mathrm{d}}\right)$ is

$f\left(\varepsilon_{\mathrm{d}}\right)=\left[\frac{\ln \left(c_{2}+c_{3} \varepsilon_{\mathrm{d}}\right)}{\ln c_{2}}\right]^{-3 / 5}$

where $c_{2}=0.011$ is a constant related to the cut-off velocity in the gaussian probability function and $c_{3}$ is a constant proportional to the ratio of coalescence to breakup coefficients. $c_{3}$ allows for differences in collision efficiencies in different systems. The value of $c_{3}$ must be determined empirically and will differ from system to system; however, it should be of the order of 1.0.

The first objective of this work is to estimate the values of the interfacial area at conditions similar to those encountered during semibatch aromatic nitration experiments and to find a suitable correlation to predict the interfacial area for the bench-scale reactor in which nitrations are carried out.

\subsection{Determination by the chemical method. Theory}

Numerous methods have been developed for the 
determination of the interfacial area. A few physical methods have been employed, such as optical techniques, e.g. light scattering or reflection, and photographic or conductivity methods [13]. In all of these methods, a local value of the interfacial area is determined.

Since its introduction, the chemical method developed by Westerterp et al. [14] has been widely used to determine the interfacial area in both gas-liquid and liquid-liquid systems. The application to liquid-liquid systems is based on the chemically enhanced extraction of reactant $A$ from liquid phase $\mathrm{L} 1$ to liquid phase L2, in which an irreversible reaction takes place with reactant B which does not penetrate into phase Ll (see Fig. $1)$.

According to the Danckwerts penetration model, the general equation for the molar flux of component $A$ is

$J_{\mathrm{A}}=\frac{k_{\mathrm{L} 2} \sqrt{1+\mathrm{Ha}^{2}}\left[m C_{\mathrm{A}}^{\mathrm{L} 1}-\left(C_{\mathrm{A} 2}^{\mathrm{L} 2} /\left(1+\mathrm{Ha}^{2}\right)\right)\right]}{1+\left[\left(m k_{\mathrm{L} 2} \sqrt{1+\mathrm{Ha}^{2}}\right) / k_{\mathrm{L} 1}\right]}$

For a second-order reaction, the consumption rate of component $\mathrm{A}$ is given as

$r=k_{1,1} C_{\mathrm{B}} C_{\mathrm{A}}^{\mathrm{L} 2}$

and the Hatta number is equal to

$\mathrm{Ha}=\frac{\sqrt{k_{1,1} C_{\mathrm{B}} D_{\mathrm{A}}}}{k_{\mathrm{L} 2}}$

Eq. (8) can be simplified at constant $C_{\mathrm{B}}$ over the film giving

$J_{\mathrm{A}}=C_{\mathrm{A}}^{\mathrm{i} 2} \sqrt{k D_{\mathrm{A}}}=C_{\mathrm{A}}^{\mathrm{L} 1} m \sqrt{k D_{\mathrm{A}}}$

when the following conditions hold:

(1) The reaction is sufficiently fast to consume all $\mathrm{A}$ in the film, so that the concentration $C_{\mathrm{A}}$ in the bulk of phase L2 equals zero.

(2) The solubility of A in phase L2 is very low, so that mass transfer limitations in phase Ll can be neglected and the concentration of $\mathrm{A}$ at the interphase

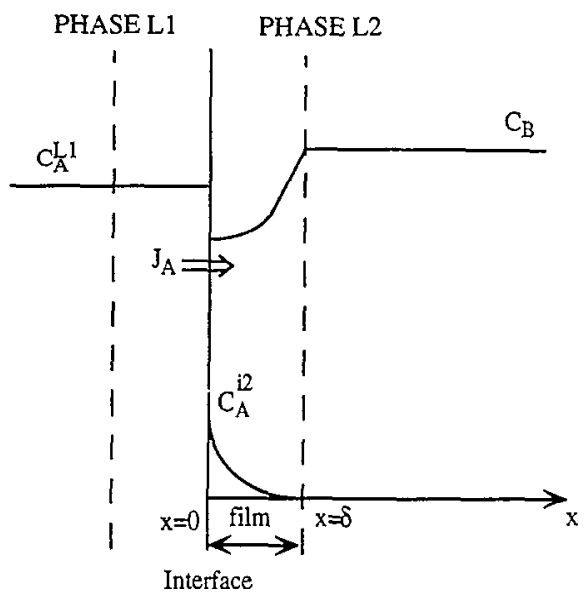

Fig. 1. Concentration profiles for chemically enhanced extraction. equals $C_{\mathrm{A}}^{\mathrm{i} 2}=m C_{\mathrm{A}}^{\mathrm{L} 1}$.

(3) Practically no depletion of component B is observed, so that $C_{\mathrm{B}}$ is approximately constant and the pseudo-first-order reaction rate constant can be assumed to be $k=k_{1,1} C_{\mathrm{B}}$.

(4) The reaction is so fast that the following relation holds:

$\mathrm{Ha}=\frac{\sqrt{k_{1,1} C_{\mathrm{B}} D_{\mathrm{A}}}}{k_{\mathrm{L} 2}}=\frac{\sqrt{k D_{\mathrm{A}}}}{k_{\mathrm{L} 2}}>3$

Under the above listed conditions, according to Eq. (11) the extraction flux $J_{\mathrm{A}}$ is a unique function of the physicochemical properties of the system and independent of the hydrodynamic conditions. Hence the term $m \sqrt{ }\left(k D_{\mathrm{A}}\right)$ in Eq. (11) can be determined separately in a liquid-liquid contactor with a well-known interfacial area, e.g. in a stirred cell. Then the effective interfacial area in any liquid-liquid stirred system can be determined if the same conditions are valid in such a system.

In this work, the extraction of diisobutylene (DIB) from a toluene solution into aqueous sulphuric acid has been chosen to measure the interfacial area, as recommended by Sankholkar and Sharma [15], because the physicochemical properties of the chosen system are expected to be very similar to toluene mononitration and other nitrations of aromatic compounds.

\subsection{Experimental determination by the chemical method}

As a small modification, we used an isomeric mixture containing 2,4,4-trimethyl-1-pentene (DIB-1) and 2,4,4trimethyl-2-pentene (DIB-2) in our experiments instead of the pure DIB-2 isomer used by Sankholkar and Sharma [15]. A pure grade isomeric mixture of DIB-1 and DIB-2 with a ratio of 3:1 supplied by Fluka was used in all the experiments. Preliminary tests indicated that the specific extraction ratc of DIB-2 from the isomeric mixture was only around $6 \%$ higher than that measured for pure DIB-2 under the same conditions by Sankholkar and Sharma [15]. It was also found that the DIB-1 isomer reacts in a similar way to DIB-2, and the ratio of the characteristic terms $m_{i} \sqrt{ }\left(k_{i} D_{\{i\}}\right)$ for DIB-1 and DIB-2 respectively equals 0.703 for a $77 \mathrm{wt} . \%$ solution of sulphuric acid; therefore, in all experiments, the effective interfacial area could be determined following the concentration decrease of DIB-1 or DIB-2 separately as well as the total concentration of DIB in the organic phase.

Analysis of DIB in the organic phase was performed with a Carlo Erba Instruments GC 6000 Vega Series gas chromatograph equipped with $15 \mathrm{~m}$ of a $0.3 \mathrm{~mm}$ fused silica capillary column with the so-called stationary phase SE 52. A Krüss interfacial tensiometer K8 was used to measure (by the ring method) the inter- 
Table 1

Characteristics of the equipment

\begin{tabular}{lllllll}
\hline Vesscl & $\begin{array}{l}\text { Diameter } \\
T(\mathrm{~mm})\end{array}$ & $\begin{array}{l}\text { Height } \\
H(\mathrm{~mm})\end{array}$ & $\begin{array}{l}\text { Volume } \\
V(\mathrm{l})\end{array}$ & $\begin{array}{l}\text { Agitator } \\
\text { type }\end{array}$ & $\begin{array}{l}\text { Impeller diameter } \\
D_{\mathrm{a}}(\mathrm{mm})\end{array}$ & $\begin{array}{l}\text { Impeller speed } \\
n_{\mathrm{n}}\left(\mathrm{s}^{-1}\right)\end{array}$ \\
\hline Stirred cell (SC) & 35 & 100 & 0.1 & TBSP & 30 & $1-2$ \\
Reactor (RC1) & 115 & 200 & 2.0 & FB45IPa & 59 & $6.6-13.3$ \\
\hline
\end{tabular}

aTBSP, two-bladed straight paddle, unbaffled; FB45IP, four-bladed $45^{\circ}$ inclined paddle, unbaffled.

facial tension between the organic phase and the sulphuric acid solution. An average value of $18.75 \mathrm{mN}$ $\mathrm{m}^{-1}$ was obtained at $308.2 \mathrm{~K}$. Experiments were performed in a stirred cell and in an $\mathrm{RCl}$ reactor calorimeter; the characteristics of the equipment are given in Table 1. All experiments were carried out under isothermal conditions at $308.2 \mathrm{~K}$.

\subsubsection{Determination of $m \sqrt{ }\left(k D_{\mathrm{A}}\right)$ in stirred cell measurements}

The organic phase containing $7 \mathrm{~mol} \%$ of a DIB isomeric mixture in toluene was contacted in the stirred cell with a known interfacial area of $F_{\mathrm{sc}}=0.9 \times 10^{-3}$ $\mathrm{m}^{2}$ with a $77 \mathrm{wt} . \%$ aqueous solution of sulphuric acid. To follow the concentration decrease of DIB in the organic phase in a reasonable time, the volume of the organic phase was always as small as $3.3 \mathrm{ml}$, while the volume of the sulphuric acid solution was $25 \mathrm{ml}$. Only the aqueous phase in the bottom part was continuously stirred to renew the interface without a pronounced vortex. The stirring rate was varied in the different experiments, samples of the organic phase with a volume of about $2-3 \mu 1$ were taken and the concentration changes were followed by chromatographic analysis of the organic phase composition.

The mass balance for DIB in the organic phase can be written as follows

$V_{\circ} \frac{\mathrm{d} C}{\mathrm{~d} t}=-F_{\mathrm{sc}} C m \sqrt{k D_{\mathrm{A}}}$

After integration of Eq. (12), we can express the concentration of DIB in the organic phase in relation to tolucne as a function of time

$\ln \frac{C_{\mathrm{A}}}{C_{\mathrm{To}}}=\ln \frac{C_{\mathrm{A}}^{0}}{C_{\mathrm{To}}}-\frac{F_{\mathrm{sc}}}{V_{\mathrm{o}}} m \sqrt{k D_{\mathrm{A}} t}$

Limitations of the assumed quasi-steady state and of the application of Eq. (11) for interfacial area measurements are discussed in Appendix B.

Typical plots obtained from measurements in the stirred cell for DIB-1 and DIB-2 as well as for the isomeric mixture are shown in Fig. 2. The straight line relationships indicate that the isomeric mixture of DIB can be used for interfacial area measurements and that the $m \sqrt{ }\left(k D_{\mathrm{A}}\right)$ value determined for the total concentration of DIB is a weighted average of the individual values of $m \sqrt{ }\left(k D_{A}\right)$ obtained for the DIB-1 and DIB-2 isomers. The $m \sqrt{ }\left(k D_{\mathrm{A}}\right)$ values obtained from the measurements performed in the stirred cell are shown in Table 2. For control purposes, two similar experiments were performed in the $\mathrm{RCl}$ reactor and are listed in Table 2. We can conclude that the $m \sqrt{ }\left(k D_{\mathrm{A}}\right)$ values do not depend on the stirrer speed or the vessel geometry. This indicates that the assumption about the absence of mass transfer resistances in the organic phase holds, because of the low solubility of DIB in the aqueous phase. According to Sankholkar and Sharma [15] the solubility of DIB in water is of the order of $10^{-5} \mathrm{kmol}$ $\mathrm{m}^{-3}$ at $303.2 \mathrm{~K}$.

\subsubsection{Interfacial area measurements in semibatch systems}

The purpose of this study was to check whether the correlations for droplet diameters, determined batchwise and at low dispersed phase volumetric fractions, may be applied in semibatch reactors.

A series of experiments was performed in a benchscale $\mathrm{RC} 1$ reactor at three different agitator speeds. In each experiment, two periods can be distinguished: the semibatch period in which the acid phase is added continuously to the reactor containing initially only the organic phase; the batch period in which the reaction continues in the dispersion after stopping the addition of acid. The temperature of the reactor contents is kept

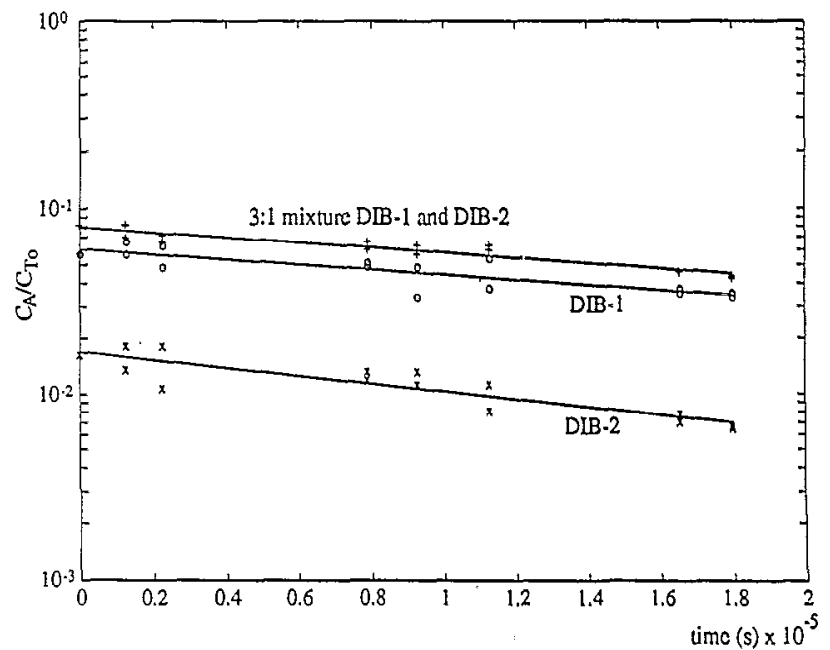

Fig. 2. Individual and total concentrations of diisobutylenes vs. time measured during a stirred cell experiment. 
Table 2

Values of $m \cdot \sqrt{ }\left(k D_{\mathrm{A}}\right)$ obtained in a stirred cell and in an $\mathrm{RC} 1$ reactor ( $T=308.2 \mathrm{~K} ; 77 \mathrm{wt} . \%$ sulphuric acid; $7 \mathrm{~mol} . \%$ DIB isomeric mixture (DIB-1 to DIB-2, 3:1)

\begin{tabular}{llll}
\hline Run & Vessel & $n_{\mathrm{a}}\left(\mathrm{s}^{-1}\right)$ & $m \sqrt{ }\left(k D_{\mathrm{A}}\right) \times 10^{9}\left(\mathrm{~m} \mathrm{~s}^{-1}\right)$ \\
\hline IFA1 & SC & 0.93 & 12.6 \\
IFA2 & SC & 1.70 & 14.7 \\
IFA3 & SC & 1.33 & 12.1 \\
IFA4 & SC & 1.38 & 14.9 \\
IFA5 & RC1 & 0.83 & 13.1 \\
IFA6 & RCl & 0.83 & 14.7 \\
\hline
\end{tabular}

Average value taken for calculations, $m \sqrt{ }\left(k D_{\mathrm{A}}\right) \times 10^{-9} \mathrm{~m} \mathrm{~s}^{-1}$.

constant during the experiments. Liquid samples of a volume of $1-2 \mathrm{ml}$ were taken during both the semibatch and batch periods to follow the progress of the reaction.

In the batch period, according to Eq. (13), the slope $K$ of a line plotted in the $\ln \left(C_{\mathrm{A}} / C_{\mathrm{To}}\right)$ vs. time domain equals

$K=-\frac{F m \sqrt{k D_{\mathrm{A}}}}{V_{\mathrm{o}}}$

The effective interfacial area $F$ in the vessel can be determined knowing the organic phase volume $V_{\mathrm{o}}$ as well as the previously determined value of $m \sqrt{ }\left(k D_{\mathrm{A}}\right)$. The interfacial area $a$ related to the total volume $V_{\mathrm{m}}$ of the dispersion at the end of acid addition can be calculated as follows

$a=\frac{F}{V_{\mathrm{m}}}=\frac{F}{V_{\mathrm{o}}+V_{\mathrm{a}}}$

In the semibatch period, the sulphuric acid solution of $77 \mathrm{wt} . \%$ is added continuously, with a constant feed rate $q_{a}$, into the reactor filled at the start with the organic phase (consisting of the isomeric mixture of DIB and toluene), i.e. the conditions during semibatch nitrations were reproduced. The effective interfacial area and the mean droplet diameter can be determined as a function of the reaction time and the volume fraction of the dispersed phase in the dispersion $\varepsilon_{\mathrm{d}}$.

Assuming ideal mixing and the absence of segregation, i.e. immediate homogenization of the freshly added amount of acid solution, the mass balance of DIB in the organic phase can be written as

$V_{\circ} \frac{\mathrm{d} C_{\mathrm{A}}}{\mathrm{d} t}=-F(t) J_{\mathrm{A}}$

where the specific extraction rate per unit of surface area $J_{\mathrm{A}}$ is expressed as in Eq. (11). Also, in this case, the conditions for mass transfer with a fast pseudofirst-order reaction are expected to hold (see Appendix B). Assuming additionally that the average droplet size equals the Sauter diameter, we can introduce
$F(t)=\frac{6 q_{\mathrm{a}} t}{d_{32}(t)}$

where $t$ is the time measured from the start of acid addition.

Supposing that the organic continuous phase volume does not change and the acid phase is fed at a constant rate, we obtain after integration

$\ln \frac{C_{\mathrm{A}}}{C_{\mathrm{To}}}=\ln \frac{C_{\mathrm{A}}^{0}}{C_{\mathrm{To}}}-\frac{6 q_{\mathrm{a}} m \sqrt{k D_{\mathrm{A}}}}{V_{\mathrm{o}}} \int_{0}^{t} \frac{t}{d_{32}(t)} \mathrm{d} t$

Since the physicochemical properties of the system and the stirrer speed can be assumed to be approximately constant during an experiment, the Weber number will also be constant. Furthermore, if $d_{32}$ is given by

$d_{32}=A \mathrm{f}\left(\varepsilon_{\mathrm{d}}\right) \mathrm{We}^{-0.6} D_{\mathrm{a}}$

we can calculate the constants for our system. Two types of correlation to estimate the interfacial area in semibatch systems have been considered.

(1) A linear correlation (see Eq. (6)) which is based on the assumption that the linear correlation for $d_{32}$, as a function of the volume fraction of the dispersed phase obtained in batch or continuous flow systems, can also be applied in semibatch systems; only the values of constants $A$ and $B$ must be fitted.

(2) The correlation of Delichatsios and Probstein [12] (see Eq. (7)) in which $A$ and $c_{3}$ must be fitted.

For the first method, introducing Eq. (19) into Eq. (18), we obtain the following integral

$\int_{0}^{t} \frac{t}{d_{32}(t)} \mathrm{d} t=\frac{1}{A D_{\mathrm{a}} \mathrm{We}^{-0.6}} \int_{0}^{t} \frac{V_{\mathrm{o}} t+q_{\mathrm{a}} t^{2}}{V_{\mathrm{o}}+q_{\mathrm{a}}(1+B) t} \mathrm{~d} t$

which can be calculated analytically. The unknown constants $A$ and $B$ can be found with non-linear regression, fitting the analytical expression to the experimental data. The calculations indicated that, due to the form of Eq. (20) and the scatter of the experimental data, the quality of the fit was independent of the value of $B$ in the range $1<B<10$. Therefore a value of $B=2$ was taken arbitrarily, in accordance with the correlation of Okufi et al. [16]; for $A$, an optimal value of 0.3512 was obtained. The experimental and calculated values are shown in Fig. 3.

In the second case, the integral expression is more complex (see Eq. (21)) and does not have an analytical solution. However, it can be solved numerically, and the unknown constants can be fitted using non-linear regression techniques. The values obtained in this case were $A=0.3029$ and $c_{3}=0.63563$ (see Fig. 4).

$$
\begin{aligned}
\int_{0}^{t} \frac{t}{d_{32}(t)} \mathrm{d} t= & \frac{1}{A D_{\mathrm{a}} \mathrm{We}^{-0.6} \ln \left(c_{3}\right)^{3 / 5}} \\
& \times \int_{0}^{t}\left[\ln \left(c_{2}+\frac{c_{3} q_{\mathrm{a}} t}{V_{\mathrm{o}}+q_{\mathrm{a}} t}\right)\right]^{3 / 5} \mathrm{~d} t
\end{aligned}
$$




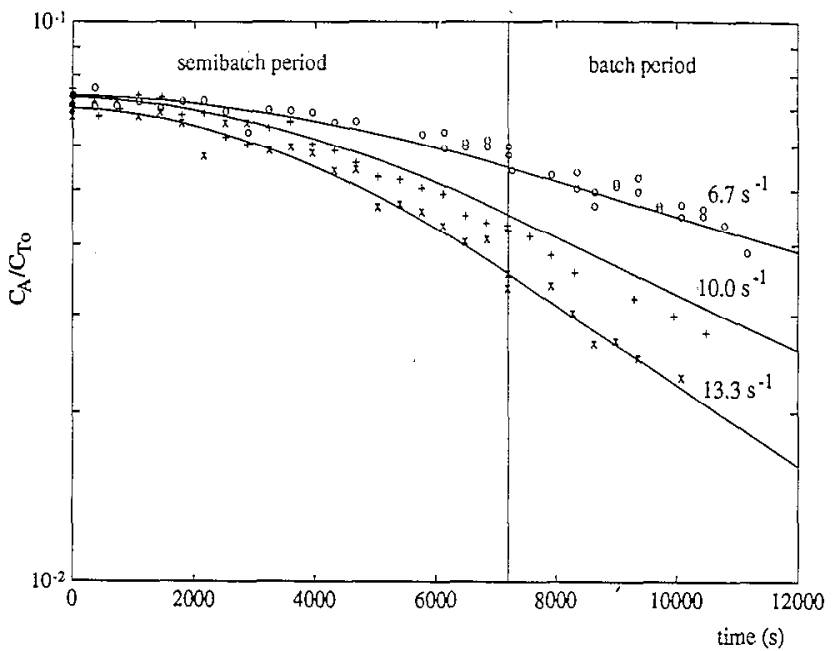

Fig. 3. Concentrations of DIB measured in a bench-scale $\mathrm{RC} 1$ reactor in semibatch and batch modes: experimental points and lines calculated using Eqs. (18) and (20). The experiments were performed at different stirrer speeds: $6.7,10.0$ and $13.3 \mathrm{rev} \mathrm{s}^{-1}$.

Both equations produce similar errors. In fact, the interfacial area calculated at $N_{\mathrm{a}}=13.3 \mathrm{~s}^{-1}$ using Eqs. (5) and (6) shows that both correlations produce similar results up to $\varepsilon_{\mathrm{d}}<0.6$ (see Fig. 5).

The correlation obtained for the system toluene-DIB and $77 \mathrm{wt} \%$ sulphuric acid has been used to predict the interfacial area during aromatic nitrations using the correlations developed for the estimation of the interfacial tension (see Appendix D).

\section{Overall conversion rate for fast nitration regime}

Benzene, toluene and chlorobenzene nitrations under normal industrial conditions, typically with $15 \mathrm{~mol} \%$ $\mathrm{HNO}_{3}, 30 \mathrm{~mol} . \% \mathrm{H}_{2} \mathrm{SO}_{4}$ and $55 \mathrm{~mol} \% \mathrm{H}_{2} \mathrm{O}$, occur in a

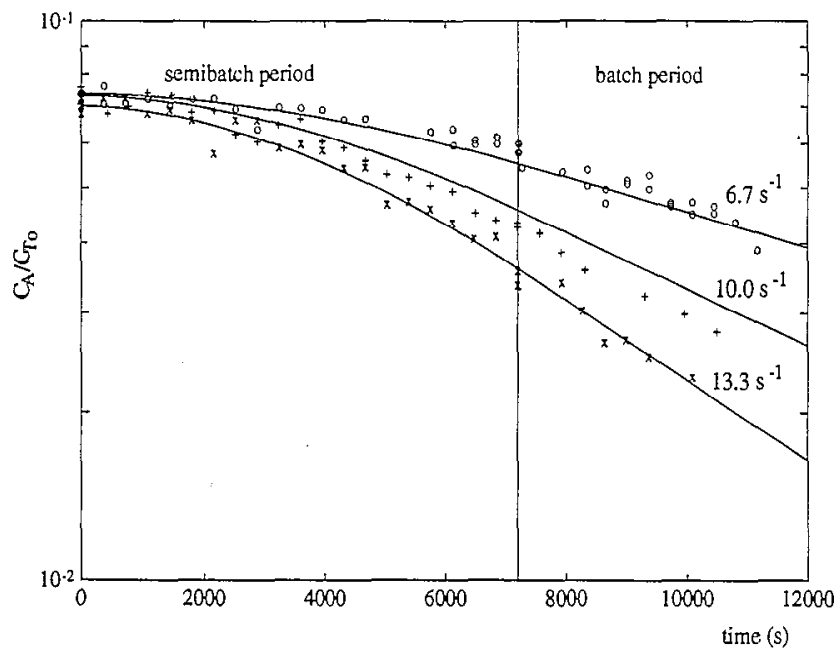

Fig. 4. Concentrations of DIB measured in a bench-scale $\mathrm{RC} 1$ reactor in semibatch and batch modes: experimental points and lines calculated using Eqs. (18) and (21). The experiments were performed at different stirrer speeds: $6.7,10.0$ and $13.3 \mathrm{rev} \mathrm{s}^{-1}$.

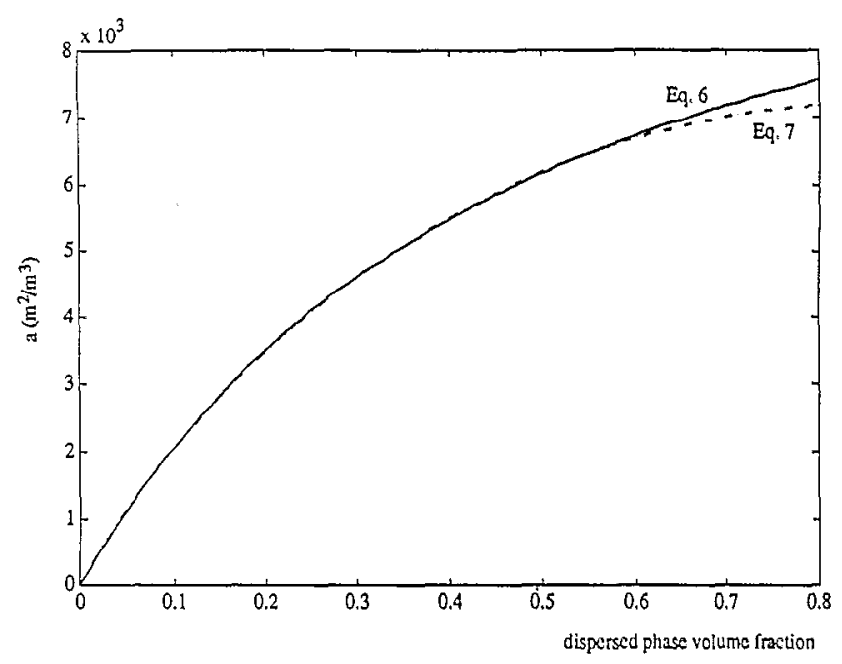

Fig. 5. Calculated interfacial areas (Eq. (19)) at 13.3 rev $\mathrm{s}^{-1}$ for the system DIB-toluene-77wt.\%sulphuric acid using fitted parameters for the linear correlation (Eq. (6)) and the correlation of Delichatsios and Probstein [12] (Eq. (7)).

two-phase system in which the organic phase is contacted with the mixed acid by agitation. Under these conditions, as has been confirmed by Schofield [1], the reaction in the organic phase is negligible and the nitronium ion mechanism is applicable.

In order to develop an overall conversion expression, the following assumptions were made.

(1) Negligible mass transfer resistance in the organic phase [3] if

$\frac{k_{\mathrm{L} 1}}{k_{\mathrm{L} 2} m E} \gg 1$

In view of the low solubility of the studied aromatic compounds in mixed acid with $m \approx(0.2-$ $0.4) \times 10^{-3}$, and the similar order of magnitude of the mass transfer coefficients in the organic and acid phases [17], the enhancement factor $E$ should be of the order of $10^{3}$ to make this assumption invalid. So, in approaching the regime of instantaneous reactions, the resistance in the organic phase will be relevant.

(2) The Hinterland ratio $A 1$ is much greater than unity. $A 1$ is the ratio of the bulk volume to the film volume in the reaction phase. For the case of reaction in the dispersed phase, $A 1$ can be expressed as

$$
A 1=\frac{(\pi / 6) d_{32}^{3}}{(\pi / 6)\left[d_{32}^{3}-\left(d_{32}-\left(D_{\mathrm{ArH}} / k_{\mathrm{L}}\right)\right)^{3}\right]}
$$

The evaluation of this ratio can be done by using the correlation of Kronig and Brink [18] for the dispersed phase mass transfer coefficient (see Appendix $\mathrm{C}$ for derivation)

$k_{\mathrm{L} 2} \approx k_{\mathrm{d}}=\frac{17.9 D_{\mathrm{ArH}}}{d_{32}}$ 
Replacing Eq. (24) into Eq. (23) gives a Hinterland ratio of 6.3. The main problem of a small Hinterland coefficient is that film theory assumes a constant $C_{\mathrm{HNO}_{3}}$ at $x=\delta$. For small values of $A 1$ and at high conversions of nitric acid, deviation may be expected due to the depletion of nitric acid concentration, e.g. in the centre of a drop. However, according to a numerical analysis carried out by Brunson and Wellek [19], even though the Hinterland ratio is relatively small, if the fluid sphere is a liquid, the film theory may be used with confidence, and the effect of the depletion of the reactant initially in the dispersed phase, i.e. nitric acid, can be neglected. This is due to the fact that, in liquid drops, the depth of penetration is generally small compared with the diameter, so that deviations are also small.

These assumptions being valid, the general approximated solution [3] for an irreversible nitration of order $(1,1)$ is

$J_{\mathrm{ArH}}=k_{\mathrm{L} 2} C_{\mathrm{ArH}}^{\mathrm{i} 2} E_{\mathrm{ArH} 0}$

where the enhancement factor $E_{\mathrm{ArH} O}$ can be calculated by trial and error from

$$
\begin{aligned}
& E_{\mathrm{ArH} 0}=\frac{\mathrm{Ha} \sqrt{\left(E_{\mathrm{ArH} \infty}-E_{\mathrm{ArH} 0}\right) /\left(E_{\mathrm{ArH} \infty}-1\right)}}{\tanh \mathrm{Ha} \sqrt{\left(E_{\mathrm{ArH} \infty}-E_{\mathrm{ArH} 0}\right) /\left(E_{\mathrm{ArH} \infty}-1\right)}} \\
& \times\left(1-\frac{C_{\mathrm{ArH}}{ }^{\mathrm{L} 2}}{C_{\mathrm{ArH}} \mathrm{i} 2 \cosh \mathrm{Ha} \sqrt{\left(E_{\mathrm{ArH} \infty}-E_{\mathrm{ArH} 0}\right) /\left(E_{\mathrm{ArH} \infty}-1\right)}}\right)
\end{aligned}
$$

The Hatta number $\mathrm{Ha}$ is defined as

$\mathrm{Ha}=\frac{\sqrt{k_{2} D_{\mathrm{ArH}_{\mathrm{H}} C_{\mathrm{HNO}}}^{\mathrm{L} 2}}}{k_{\mathrm{L} 2}}$

$E_{\mathrm{ArH}}$, the maximum possible enhancement factor for instantaneous reactions, is given by

$E_{\mathrm{ArH} \infty}=1+\frac{D_{\mathrm{HNO}_{3}} C_{\mathrm{HNO}_{3}}^{\mathrm{L2}}}{D_{\mathrm{ArH}} C_{\mathrm{ArH}}^{\mathrm{i} 2}}$

Three limiting solutions can be obtained [3].

(1) Slow liquid-liquid reactions. In this case, the rate of mass transfer is not enhanced by the reaction occurring, and the reaction mainly proceeds in the bulk of the reaction phase, i.e.

$J_{\mathrm{ArH}}=k_{\mathrm{L} 2}\left(C_{\mathrm{ArH}}^{\mathrm{i} 2}-C_{\mathrm{ArH}}^{\mathrm{L} 2}\right)$

For such situations, it must be checked that the condition $\mathrm{Ha}<0.3$ holds in the reactor and that the concentration drop over the film of the component transferred is less than $5 \%$, or $C_{\mathrm{ArH}}^{\mathrm{L} 2} / C_{\mathrm{AxH}}^{\mathrm{i} 2}>0.95$ [20]. In this case, the overall conversion rate expression is

$$
R=\varepsilon_{\mathrm{L} 2} k_{2} C_{\mathrm{ArH}}^{\mathrm{L} 2} C_{\mathrm{HNO}_{3}}^{\mathrm{L} 2}
$$

(2) Fast liquid-liquid reactions with $\mathrm{Ha}>2$. In this case, the rate of mass transfer is enhanced by the reaction, and the bulk of the acid phase in which the reaction takes place is no longer important, i.e. the concentration of the aromatic component transferred into the acid phase becomes negligible. If $2<\mathrm{Ha} \ll D_{\mathrm{HNO}_{3}} C_{\mathrm{INO}_{3}} / D_{\mathrm{ArII}} C_{\mathrm{ArII}}^{\mathrm{i}}$ holds, then $E=\mathrm{Ha}$ and the conversion rate becomes

$R=a k_{\mathrm{L} 2} E C_{\mathrm{ArH}}^{\mathrm{i} 2}=a \sqrt{k_{2} D_{\mathrm{ArH} C_{\mathrm{HNO}_{3}}^{\mathrm{L} 2}}} C_{\mathrm{ArH}}^{\mathrm{i} 2}$

Hence $J_{\mathrm{ArH}}$ is no longer dependent on the mass transfer coefficient. When $\mathrm{Ha}$ is not much smaller than $D_{\mathrm{HNO}_{3}} C_{\mathrm{HNO}_{3}} / D_{\mathrm{ArH}} C_{\mathrm{ArH}}^{\mathrm{i} 2}$, diffusion limitation of $\mathrm{HNO}_{3}$ occurs and the enhancement factor must be calculated by iteration using Eq. (26). Since in the cases studied $A 1 \mathrm{Ha}^{2} \gg 1$, the approximation $C_{\mathrm{ArH}}^{\mathrm{L} 2} \approx 0$ holds.

(3) Instantaneous liquid-liquid reactions. The reaction rate is so high that the aromatic compound and the nitronium ion do not occur simultaneously at the same place, and the reaction zone reduces to a plane in the boundary layer of the reaction phase. Here

$R=a k_{\mathrm{L} 2} E_{\mathrm{ArH} \infty} C_{\mathrm{ArH}}^{\mathrm{i} 2}$

In this case, the concentration drop in the non-reaction phase becomcs important if $E_{\mathrm{ArH} \infty}$ approximates to high values, i.e. $10^{3}-10^{4}$; under such circumstances, the assumptions derived previously are no longer valid.

By modifying the sulphuric acid strength, it is possible to work in different regimes. Moreover, in a semibatch process, the regime of nitration may change from mass transfer control to chemical control; in a di- or tri-nitration process, the aromatic ring will be deactivated by the introduction of the nitro group and, as a consequence, the regime may change.

\section{Experimental study: model verification using reaction calorimetry}

In this work, the regime of fast liquid-liquid reactions was studied in a reaction calorimeter (RC1). This apparatus provides an accurate measurement of the heat removal from the reactor which, through a heat balance, is used to determine the rate of heat generation in the reaction mass and hence the rate of conversion. The precision of this calorimetric evaluation [21] depends on the correct representation of all the secondary heat effects, such as heat losses, stirring power supply, heat taken up by reactor wall and dilution heat (see Ref. [22]). Here, the heat of dilution, which plays an important role in the total heat generated during nitration, has been evaluated using a model developed in previous work [23]. Furthermore, the selectivity and 
Table 3

Isothermal nitration experiments in the mass transfer regime: operating and initial conditions

\begin{tabular}{lllll}
\hline Compounds & $\begin{array}{l}\text { Temperature } \\
(\mathrm{K})\end{array}$ & $\begin{array}{l}x \\
(\mathrm{wt} . \%)\end{array}$ & $\begin{array}{l}n_{\mathrm{u}} \\
\left(\mathrm{s}^{-1}\right)\end{array}$ & $\begin{array}{l}\text { Feeding time } \\
(\mathrm{h})\end{array}$ \\
\hline Benzene, toluene and chlorobenzene & $298.2-318.2$ & $70-80$ & $6.67-13.3$ & $2-4$ \\
\hline
\end{tabular}

yields were directly determined from concentration measurements by gas chromatography [24] and then compared with the reaction rate determined by calorimetric measurements [25]. Hence two independent experiments, based on calorimetric determination and chemical analysis, were employed to obtain the experimental values of the conversion rates.

The slow liquid-liquid reaction regime was studied in previous work [2], and it takes place when low sulphuric acid strengths, i.e. below $60 \mathrm{wt} . \% \mathrm{H}_{2} \mathrm{SO}_{4}$, are used.

The experiments in the reaction calorimeter were carried out in such a way as to ensure that the overall reaction rate was mass transfer controlled, at least during the first part of the reaction. These conditions were achieved by operating in a semibatch mode and by using mixed acid with a high sulphuric acid strength of $70-80$ wt. $\%$ in water. The operating conditions are summarized in Table 3 . In all the reported experiments, the mixed acid was added to the aromatic compound and hence the acid formed the dispersed phase. Phase inversion was not observed during these experiments [26].

\subsection{Toluene mononitration experiments}

A series of toluene mononitration experiments was carried out in the $\mathrm{RC1}$ reaction calorimeter to study the influence on the overall conversion rate of operating and initial conditions, such as the temperature, stirrer spccd, feed rate and sulphuric acid strength.

Fig. 6 shows the calculated and simulated reaction rates as a function of the sulphuric acid strength, whereas in Fig. 7, the measured and simulated concentration-time profiles for $o$-mononitrotoluene $(o-\mathrm{MNT})$, $p$-mononitrotoluene ( $p$-MNT) and $m$-mononitrotoluene ( $m$-MNT) are shown. The instantaneous reaction rate (no accumulation of nitric acid in the reactor) is also plotted. Mixed acids of different sulphuric acid strengths, i.e. $x=74.8,72.4$ and $70.2 \mathrm{wt} . \%$, were added in $4 \mathrm{~h}$. The reactor temperature and stirrer speed were $308.2 \mathrm{~K}$ and $6.67 \mathrm{~s}^{-1}$ respectively. The slow start of the reaction and the initial accumulation of nitric acid are caused by the relatively high solubility of nitric acid in the organic phase. This nitric acid is not available for nitration as the reaction takes place in the acid phase.

Fig. 8 shows the calculated and simulated conversion rates as a function of temperature for three semibatch toluene nitration experiments. The instantaneous reaction rate (no accumulation of nitric acid in the reactor) is also plotted. The mixed acid of sulphuric acid strength $x=78.9$ wt. $\%$ was added in $2 \mathrm{~h}$. The stirrer speed was $6.67 \mathrm{~s}^{-1}$. As can be observed, as the temperature increases, the behaviour of the nitration rate closely approaches an instantaneous reaction, which decreases as the volume increases. Even for the experiment at $308.2 \mathrm{~K}$ (Fig. 8(c)), which during the intermediate period is practically limited by the feed rate, there is always an initial accumulation of nitric acid (see Fig. 8(d)); this accumulation becomes more important as the temperature decreases, reaching values which, under adiabatic conditions, i.e. a cooling system failure, could produce temperature increases higher than $70 \mathrm{~K}$.

\subsection{Benzene mononitration experiments}

A series of benzene nitration experiments was carried out in the $\mathrm{RCl}$ reactor to study this reaction. Fig. 9 shows the experimental and simulated conversions for benzene and nitrobenzene during two experiments for different mixed acid compositions. The simulated accumulation of nitric acid is also shown. At a strength of $75.0 \mathrm{wt} . \%$ of sulphuric acid, the maximum accumulation, which occurs at the end of the addition period, is $1.1 \mathrm{~mol}$, whereas in the experiment with an acid strength of $72.0 \mathrm{wt} . \%$, the accumulation increases up to $1.7 \mathrm{~mol}$. In both experiments, the mixed acid was added
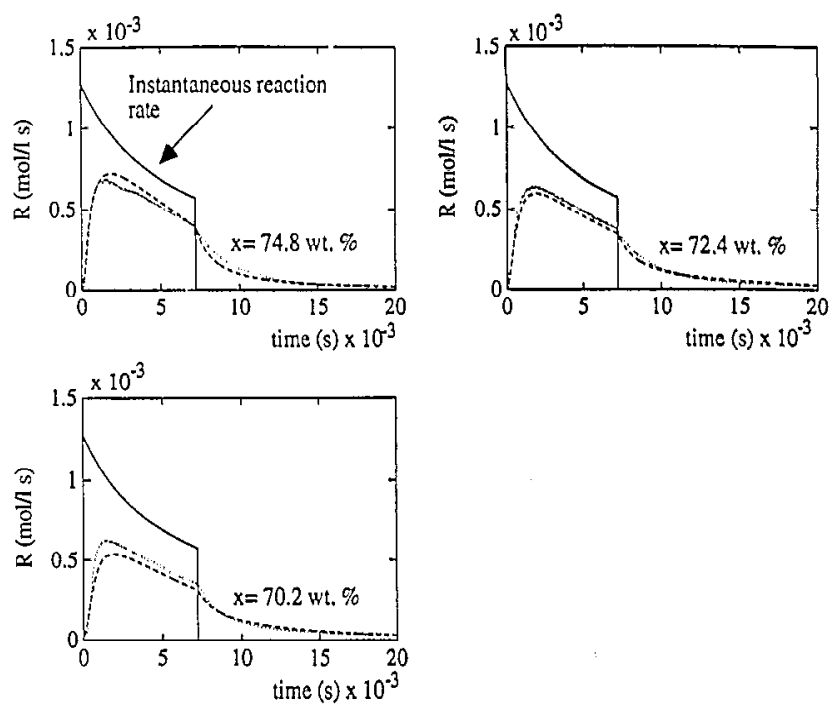

Fig. 6. Experimental (dotted line) and simulated (broken line) conversion rates $\left(\mathrm{mol} \mathrm{l}^{-1} \mathrm{~s}^{-1}\right)$ for semibatch toluene mononitrations. 

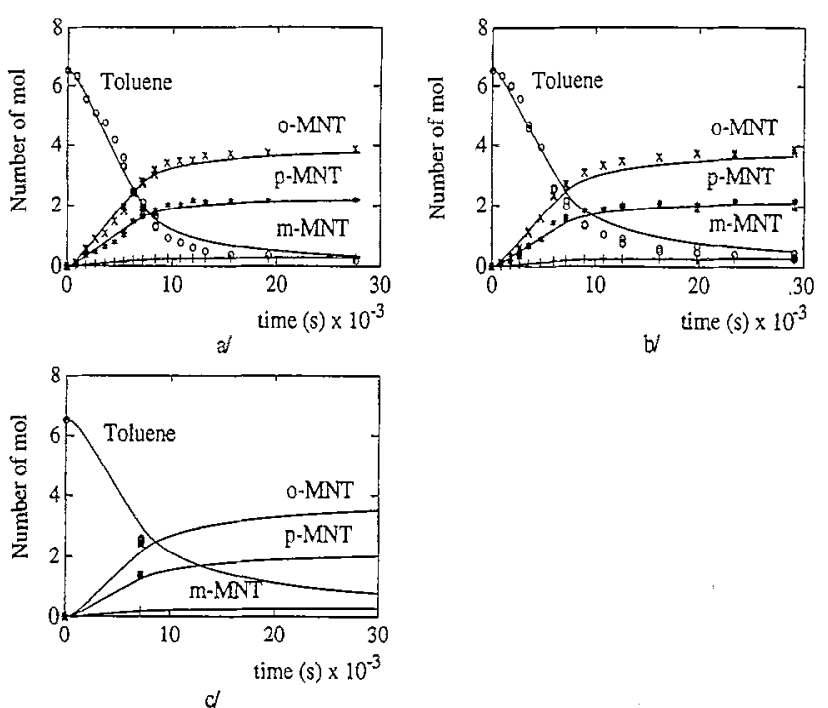

Fig. 7. Experimental and simulated conversions for semibatch toluene mononitrations: (a) $x=74.8 \mathrm{wt} . \%$; (b) $x=72.4 \mathrm{wt} . \%$; (c) $x=70.6$ wt. $\%$.

in $2 \mathrm{~h}$, and the reactor temperature and stirrer speed were $303.2 \mathrm{~K}$ and $8.33 \mathrm{~s}^{-1}$ respectively.

Under industrial conditions, the nitration rates of benzene and toluene are of a similar magnitude, whereas, in homogeneous conditions, the relation between the observed second-order reaction rates is (at a sulphuric acid strength of $70.0 \mathrm{wt} . \%$ ) approximately 1:8.5. This is due to a combination of different factors which affect the overall conversion rate. The most important is the difference in solubility, e.g. the relation at $298 \mathrm{~K}$ in sulphuric acid (70.0 wt.\%) is 1:0.33. Moreover, the change in the physical and transport properties of the reaction mixture influences the interfacial area, mass transfer and diffusion coefficients, e.g. the
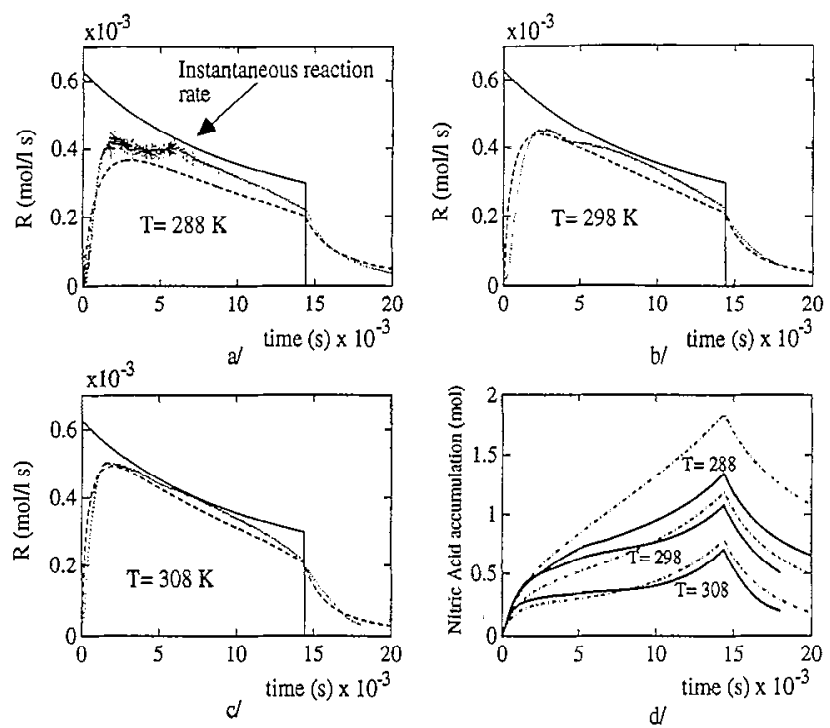

Fig. 8. Experimental and simulated conversion rates $\left(\mathrm{mol}^{-1} \mathrm{~s}^{-1}\right)$ for semibatch toluene mononitrations: (a) $T=288 \mathrm{~K}$; (b) $T=298 \mathrm{~K}$; (c) $T=308 \mathrm{~K}$. (d) Experimental and simulated nitric acid accumulation during the experiments.
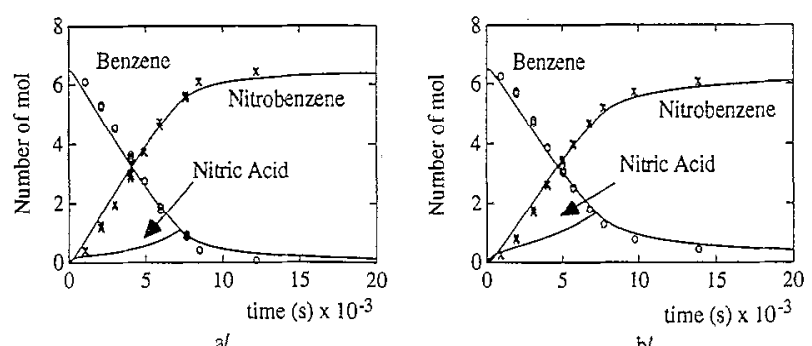

Fig. 9. Experimental and simulated conversions for benzene and nitrobenzene during semibatch nitrations: (a) $x=75.0 \mathrm{wt.} \%$; (b) $x=72.0 \mathrm{wt} . \%$.

relation between the diffusion coefficients of benzene and toluene at $298 \mathrm{~K}$ is $1: 0.9$. The relationship between the Sauter mean diameter for benzene and toluene in similar conditions is 1:0.96, which implies that benzene droplets (in the case of the dispersed organic phase) will be smaller and the interfacial area will be slightly higher.

\subsection{Chlorobenzene mononitration experiments}

A chlorobenzene nitration experiment was carried out in the $\mathrm{RCl}$ reactor to study the reaction. Mixed acid with a sulphuric acid strength of $77.9 \mathrm{wt} . \%$ was added in $2 \mathrm{~h}$, and the reactor temperature and stirrer speed were $313.2 \mathrm{~K}$ and $6.67 \mathrm{~s}^{-1}$ respectively. Fig. 10 shows the experimental and simulated conversions for chlorobenzene and nitrochlorobenzenes. As can be observed, no meta isomer was found experimentally in the gas chromatographic analysis. In this case, nitric acid accumulation is higher than for benzene, although the reactor temperature and sulphuric acid strengths were higher.

\section{Discussion and conclusions}

The model employed, based on the effective interfacial area between two liquids and the description of mass transfer with reaction using the film model, is the
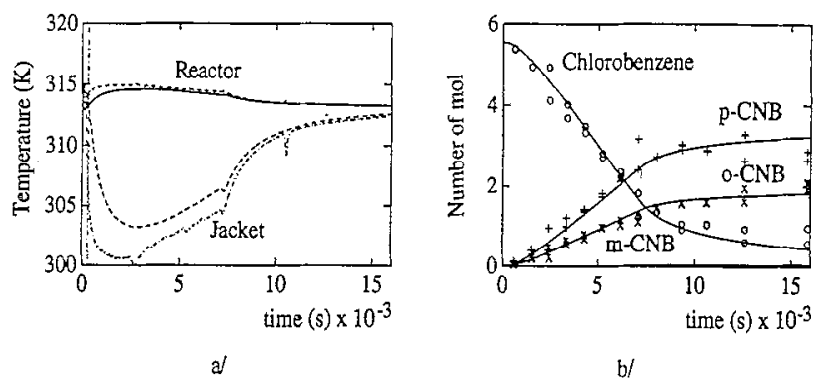

Fig. 10. Expcrimcntal and simulated temperatures and conversions for chlorobenzene and mononitrochlorobenzenes during semibatch nitration: (a) reactor and jacket temperatures; (b) conversions of chlorobenzene, $o$-nitrochlorobenzene ( $o$-CNB) and $p$-nitrochlorobenzene $(p-\mathrm{CNB})$. 
simplest approach. Due to the complexity and non-idealities of the mixtures studied, and the data available, this model is adequate. The results indicate that the nitration of benzene, toluene and chlorobenzene at $\mathrm{H}_{2} \mathrm{SO}_{4}$ strengths of $70-80 \mathrm{wt} . \%$, temperatures between 298.2 and $318.2 \mathrm{~K}$ and in the bench-scale reactor occurs in the fast reaction regime. Under these conditions, the mass transfer rate does not influence directly the overall conversion; the conversion is affected by the interfacial area, the distribution coefficients and the Hatta number.

The correlations obtained for the system tolueneDIB-77wt.\%sulphuric acid have been used to predict the interfacial area during aromatic nitrations. The effective interfacial areas determined in semibatch experiments indicate that the literature correlations can be used, although the constants deviate. This is probably caused by the specific properties of the system investigated here (strongly coalescing dispersion), the absence of baffles in the $\mathrm{RCl}$ reactor and the type of impeller installed, in comparison with the regions investigated in the literature, i.e. close to the impeller and at low dispersed phase volume fractions. The correlations produce droplet diameters between 0.3 and $0.8 \mathrm{~mm}$, with effective interfacial areas similar to those found by Fernandez and Sharma [27] during an investigation of the two-phase alkaline hydrolysis of 2-ethylhexyl formate in $2 \mathrm{M} \mathrm{NaOH}$ solution.

The distribution cocfficients of aromatic compounds limit the maximum possible concentration in the acid reaction phase. The low solubility of the aromatic compounds studied (with $m_{\mathrm{ArH}} \approx 10^{-4}$ ) allows the mass transfer resistance in the non-reactive phase to be neglected (it becomes important for $m \mathrm{Ha}>0.1$, i.e. for more reactive or more soluble aromatics, or at high sulphuric acid strengths at which the instantaneous reaction regime occurs). Moreover, nitric acid accumulation is due to these low values of $m_{\mathrm{ArH}}$. Danger of accumulation is imminent if the conversion rate is lower than the molar feed rate per unit volume. Evaluation for typical parameter values yields the following criterion for the occurrence of accumulation in our reactor: $a \mathrm{VmHa}<2$ [28]. These conditions hold in some of the experiments and can be observed, for example, in Figs. 8 and 9. Finally, another important value is the distribution coefficient of the nitric acid dissolved in the aromatic phase. This nitric acid cannot change into nitronium ion $\mathrm{NO}_{2}^{+}$(the nitrating agent) and hence is not available for nitration.

\section{Acknowledgements}

The authors are grateful to Dr. C. Barcons, Dr. T.J. Snee and J. Ligthart for collaboration during the experiments.

\section{Appendix A: Nomenclature}

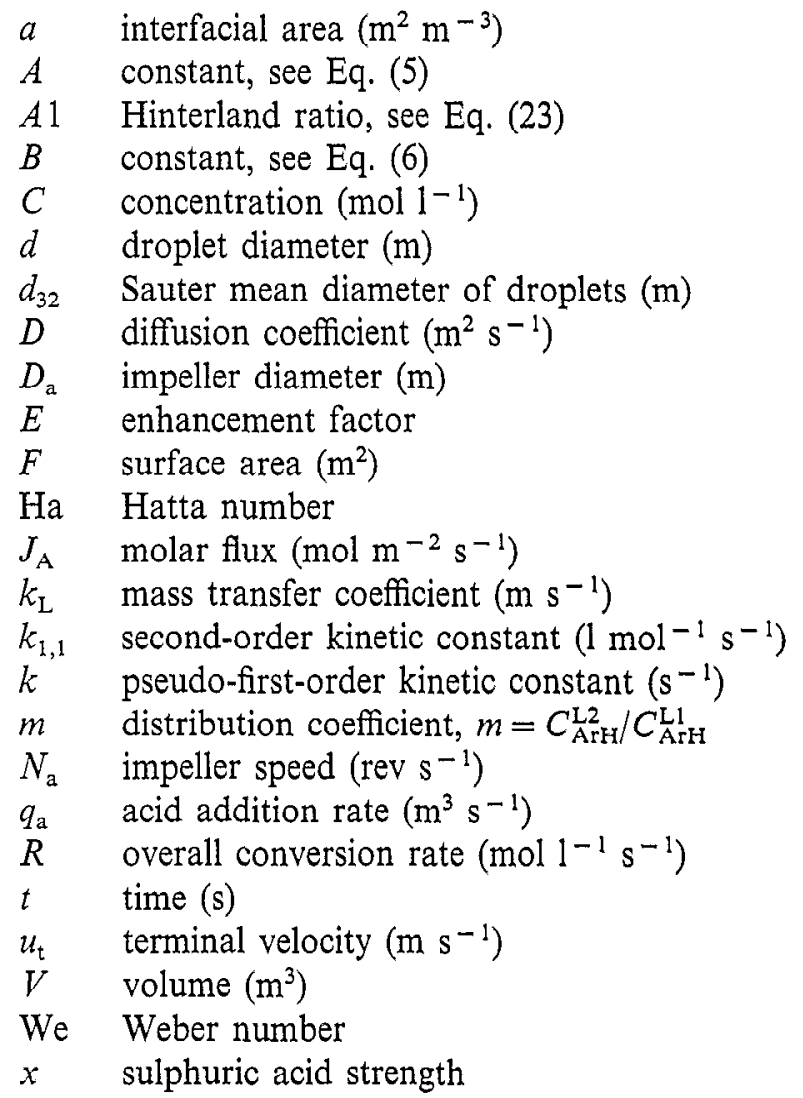

\section{Greek letters}

$\begin{array}{ll}\gamma & \text { surface tension }\left(\mathrm{N} \mathrm{m}^{-1}\right) \\ \delta & \text { film thickness } \\ \varepsilon & \text { ratio } \\ \varepsilon_{\mathrm{d}} & \text { dispersed phase volume fraction } \\ \mu & \text { kinematic viscosity }(\mathrm{Pa} \mathrm{s}) \\ \rho & \text { density }\left(\mathrm{kg} \mathrm{m}^{-3}\right) \\ \sigma & \text { interfacial tension }\left(\mathrm{N} \mathrm{m}^{-1}\right)\end{array}$

\section{Subscripts and superscripts}

$\begin{array}{ll}\text { A } & \text { diisobutylene } \\ \text { a } & \text { acid phase } \\ \text { ArH } & \text { aromatic compound } \\ \mathrm{B} & \text { sulphuric acid } \\ \mathrm{Be} & \text { benzene } \\ \mathrm{c} & \text { continuous phase } \\ \mathrm{d} & \text { dispersed phase } \\ \text { i1 } & \text { aqueous interphase } \\ \text { i2 } & \text { organic interphase } \\ \mathrm{L} 1 & \text { aqueous phase } \\ \mathrm{L} 2 & \text { organic phase } \\ \mathrm{m} & \text { reaction mixture } \\ \text { o } & \text { organic phase } \\ \text { To } & \text { toluene }\end{array}$




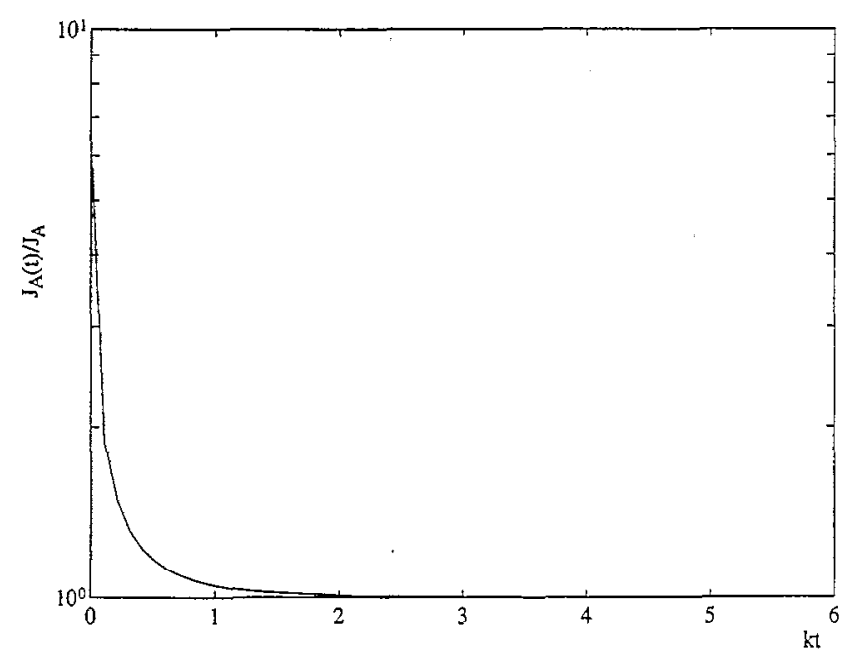

Fig. 11. Ratio of the mass fluxes determined for steady and nonsteady state conditions (constant concentration at the interface surface).

\section{Appendix B: Check on the validity of the assumed quasi-steady state for the interfacial area calculation}

For non-steady state conditions using the Higbie penetration model, the mass balance for a pseudo-firstorder irreversible reaction reads

$$
\frac{\partial C_{\mathrm{A}}}{\partial t}=D_{\mathrm{A}} \frac{\partial^{2} C_{\mathrm{A}}}{\partial x^{2}}-k C_{\mathrm{A}}
$$

with the boundary conditions

$$
\begin{aligned}
& t=0 ; C_{\mathrm{A}}=0 \text { at } 0<x<\infty \\
& t>0 ; C_{\mathrm{A}}=C_{\mathrm{A}}^{\mathrm{i} 2} \text { at } x=0 \\
& t>0 ; C_{\mathrm{A}}=0 \text { at } x \rightarrow \infty
\end{aligned}
$$

Solving Eq. (B1) with the boundary conditions (Eqs. (B2a)-(B2c)) gives, for a bulk concentration of $\mathrm{A}$ equal to zero, the flux through the interface at time $t$ as follows

$J_{\mathrm{A}}(0, t)=C_{\mathrm{A} 2} \sqrt{k D_{\mathrm{A}}}\left[\operatorname{erf}(\sqrt{k t})+\frac{\exp (-k t)}{\sqrt{\pi k t}}\right]$

The ratio of the non-steady state and steady state fluxes, given by Eqs. (B3) and (11) respectively, is equal to

$\varepsilon=\frac{J_{\mathrm{A}}(0, t)}{J_{\mathrm{A}}}=\operatorname{erf}(\sqrt{k t})+\frac{\exp (-k t)}{\sqrt{\pi k t}}$

The values of the ratio $\varepsilon$ are plotted in Fig. 11 as a function of time. For $k t>2$, the mass transfer rate approaches a stationary minimum value given by Eq. (11). The estimated value of $k$ for the system used in our investigations (77 wt.\% of $\mathrm{H}_{2} \mathrm{SO}_{4}, \mathrm{DIB}$ and toluene) is of the order of $k \approx 1 \mathrm{~s}^{-1}$. In this case, ratio $\varepsilon$ becomes identical at unity after a time as short as $1 \mathrm{~s}$.
Appendix C: Estimation of mass transfer coefficients in liquid-liquid systems

During the past decades, a considerable amount of data have been collected on physical mass transfer in dispersed systems (for a review, see Laddha and Degaleesan [17] and Hanson [29]). The estimation of the overall mass transfer coefficient calls for a knowledge of the dispersed phase $\left(k_{\mathrm{d}}\right)$ and continuous phase $\left(k_{\mathrm{c}}\right)$ coefficients. These individual mass transfer coefficients have been correlated for many systems by analogy with heat transfer coefficients in terms of the hydrodynamic behaviour and physical properties, such as

$\mathrm{Sh} \propto \mathrm{Re}^{n_{1}} \mathrm{Sc}^{n_{2}}$

where $\mathrm{Sh}, \mathrm{Re}$ and $\mathrm{Sc}$ are defined as

$$
\begin{aligned}
& \mathrm{Sh}=\frac{k d}{D} \\
& \mathrm{Re}=\frac{d v \rho}{\mu} \\
& \mathrm{Sc}=\frac{\mu}{D \rho}
\end{aligned}
$$

where $d$ and $v$ are a linear dimension and velocity characterizing the dispersion, e.g. drop size and drop velocity, $D$ is the coefficient of molecular diffusion of the species considered and $\rho$ and $\mu$ are the density and viscosity of the fluid respectively. In the case of aromatic nitrations, the reaction proceeds in the acid phase, and hence the aromatic compound diffuses from the organic (L1) to the acid (L2) phase and reacts in the acid phase. Two different cases can be considered.

(1) The organic is the dispersed phase and the acid is the continuous phase as, for example, in the slow liquid-liquid regime during batch nitrations [2].

(2) The organic is the continuous phase and the acid is the dispersed phase as in the case of semibatch nitrations in the fast regime.

The overall mass transfer coefficient, based on L1 and L2 phases respectively, can be written for physical transport without reaction as

$\frac{1}{k_{\mathrm{ov}}(\mathrm{L} 1)}=\frac{1}{k_{\mathrm{L} 1}}+\frac{1}{m k_{\mathrm{L} 2}}$

$\frac{1}{k_{\mathrm{ov}}(\mathrm{L} 2)}=\frac{m}{k_{\mathrm{L} 1}}+\frac{1}{k_{\mathrm{L} 2}}$

The mass transfer resistance in the organic phase L1 can be neglected if the phase contains pure reactant without solvent as in the case of the aromatic nitrations studied. If there is a solvent or product formed due to reaction which is dissolved in the organic phase, the validity of neglecting the mass transfer resistance in the organic phase must be examined. In the case of mass 
transfer without chemical reaction in liquid-liquid dispersions, the order of magnitude of the liquid mass transfer coefficients $k_{\mathrm{c}}$ and $k_{\mathrm{d}}$ normally lies in the range between $10^{-4}$ and $10^{-5} \mathrm{~m} \mathrm{~s}^{-1}$ [17], and can sometimes reach lower values, such as $5 \times 10^{-6} \mathrm{~m} \mathrm{~s}^{-1}$, in viscous solutions or large drops [29]. As the value of $m$ is approximately $10^{-4}$ under the conditions studied [2], the overall mass transfer coefficient can be equated to $k_{\mathrm{L} 2}$ and the resistance in the organic phase can be neglected. Hence the two cases are as follows.

\section{Continuous phase mass transfer coefficient}

The following empirical correlation developed by Calderbank and Moo-Young [30], and experimentally validated over a wide range of operating conditions [31], may be used to determine the mass transfer coefficient in the continuous phase $k_{\mathrm{L} 2}$ in liquid-liquid dispersion systems [32]

$k_{\mathrm{L} 2}=0.13\left(\frac{P \mu_{\mathrm{c}}}{V_{\mathrm{d}} \rho_{\mathrm{c}}^{2}}\right)^{1 / 4}\left(\frac{\mu_{\mathrm{c}}}{\rho_{\mathrm{c}} D_{\mathrm{ArH}}}\right)^{-2 / 3}$

where $P$ refers to the power dissipated by the stirrer

$P=\phi^{\prime} \rho_{\mathrm{m}} n_{\mathrm{a}}^{3} D_{\mathrm{a}}^{5}$

and $\phi^{\prime}$ may be considered as a constant $\left(\phi^{\prime}=2.2\right)$ $[22,33]$.

Chapman et al. [34], in a series of toluene nitration experiments using acid strengths between $76 \%$ and $79 \%$, estimated the mass transfer coefficient to be $k_{\mathrm{L} 2}=1.03 \times 10^{-5} \mathrm{~m} \mathrm{~s}^{-1}$. This value is in agreement with typical values found in liquid-liquid systems, e.g. Fernandez and Sharma [27] found values in the range $(1.13-1.6) \times 10^{-5} \mathrm{~m} \mathrm{~s}^{-1}$ for the system $n$-hexylacetate and $1 \mathrm{M} \mathrm{NaOH}$ solution. Using the correlation given in Eq. (C7) and the experimental data from Chapman et al. [34], the value obtained for $k_{\mathrm{L} 2}$ is $1.1 \times 10^{-5} \mathrm{~m} \mathrm{~s}^{-1}$, which is in agreement with that derived from experiments reported in the literature.

\section{Dispersed phase mass transfer coefficient}

In this case, the mass transfer coefficient will depend on the behaviour of the drop and whether or not it is rigid [29].

For a rigid droplet, Treybal [35] presents the following relationship for spheres with no circulation and with transfer by pure molecular diffusion

$\mathrm{Sh}_{\mathrm{d}}=\frac{2 \pi^{2}}{3}$

where $\mathrm{Sh}_{\mathrm{d}}$ is the Sherwood number for the dispersed phase, defined as

$\mathrm{Sh}_{\mathrm{d}}=\frac{k_{\mathrm{d}} d_{32}}{D}$ and hence

$k_{\mathrm{d}}=\frac{2 \pi^{2} D}{3 d_{32}}$

For drops with internal circulation and/or oscillations, the mixing in the drop can be laminar or turbulent. For the regime of laminar circulation, the relation of Kronig and Brink [18] is generally accepted [29]

$k_{\mathrm{d}}=\frac{17.9 D}{d_{32}}$

This correlation is restricted to regimes where $\operatorname{Re}<1$. Johnson and Hamielec [36] found that it can be used in some cases for higher values of Re. For drops with turbulent circulation, the model of Handlos and Baron [37], which has been experimentally verified by Wellek and Skelland [38] and Johnson and Hamielec [36], can be used as a good approximation

$k_{\mathrm{d}}=0.00375 u_{\mathrm{t}}\left(\frac{\mu_{\mathrm{c}}}{\mu_{\mathrm{c}}+\mu_{\mathrm{d}}}\right)$

Schroeder and Kintner [39] concluded that no oscillations accur for $\operatorname{Re}<200$.

In the case of the reaction calorimeter, the usual drop diameter lies between 0.3 and $0.8 \mathrm{~mm}$. In semibatch experiments, the mixed acid is added to the reactor, so the acid phase will be the dispersed phase. Defining the interface number as [40]

$\sigma^{*}=\sigma\left(\frac{\rho_{\mathrm{c}}^{2}}{g \Delta \rho \mu_{\mathrm{c}}^{4}}\right)^{1 / 3}$

which is a measure of the resistance of the interface against deformation, and calculating the diameter number according to Wesselingh [40]

$d_{\max }^{*}=4 \sqrt{\sigma^{*}}$

which applies for drops in liquids when $\left(\mu_{\mathrm{d}} / \mu_{\mathrm{c}}\right) \geqslant 2$, we find for a typical nitration reaction that $\dot{\sigma}^{*}$ lies between 400 and 3500 and $d^{*} \approx 80-240$. These values indicate that mixed acid drops do not behave as rigid drops. The power introduced by the turbine stirrer used varies between 0.2 and $3.2 \mathrm{~kW} \mathrm{~m}^{-3}$. For liquids with low viscosities between 1 and $10 \mathrm{cP}$ and high interfacial tensions between 25 and $45 \mathrm{~m} \mathrm{~N} \mathrm{~m}^{-1}$, the terminal velocity can be estimated using the correlation of $\mathrm{Hu}$ and Kintner [41]

$u_{\mathfrak{t}}=\sqrt{\frac{4 g d_{32} \Delta \rho}{3 \rho C_{D}}}$

where $C_{\mathrm{D}}$ is a drag coefficient which is a function of the shape of the particle, the physical properties of the system and the Reynolds number. An estimate leads to a terminal velocity of $0.03-0.06 \mathrm{~m} \mathrm{~s}^{-1}$ and an internal Reynolds number between 1.5 and 20. For these values, the general diagram derived by Wesselingh [40] tells us that mixed acid drops behave as non-rigid drops with 
laminar circulation; as a consequence, correlation Eq. (C12) should be used.

\section{Appendix D: Estimation of the interfacial tension between mixed acid and aromatic compounds}

The liquid-liquid interfacial tension has a significant effect on the degree of dispersion and on the stability of the dispersed system. No method is available to predict interfacial tensions in multicomponent mixtures from pure component or binary data (see Backes et al. [42]). Therefore empirical correlations must be developed.

Antonow's rule [35] states that the interfacial tension between two saturated liquid phases equals the difference between their individual surface tensions with air

$\sigma_{12}=\left|\gamma_{1}^{\prime}-\gamma_{2}^{\prime}\right|$

This equation is valid only for a restricted class of liquid pairs and cannot be relied upon [35]. Donahue and Bartell [43] proposed the following empirical correlation for a binary system

$\sigma_{12}=a-b \log \left(x_{1}^{\prime \prime}+x_{2}^{\prime}\right)$

where $x_{1}^{\prime \prime}$ refers to the molar concentration of the organic compound in the aqueous phase and $x_{2}^{\prime}$ refers to the molar concentration of water in the organic phase; $a$ and $b$ are constants. This correlation was modified by Treybal [35] for ternary systems to give

$\sigma_{12}=a-b \log \left[x_{1}^{\prime \prime}+x_{2}^{\prime}+(1 / 2)\left(x_{3}^{\prime}+x_{3}^{\prime \prime}\right)\right]$

where $x_{3}^{\prime}$ and $x_{3}^{\prime \prime}$ refer to the molar concentrations of the solute in both phases. Good and Elbing [44] proposed the following correlation

$\sigma_{12}=\gamma_{1}+\gamma_{2}-2 \Phi_{12} \sqrt{\gamma_{1} \gamma_{2}}$

where $\Phi_{12}$ is an interaction parameter. For the prediction of $\Phi_{12}$, Good and Elbing [44] developed a theoretical model based on the intermolecular forces between the two liquid phases, such as the dipole-dipole force, hydrogen bonds and the Kihara dispersion potential. Recently, $\mathrm{Li}$ and $\mathrm{Fu}$ [45] have proposed a new method for predicting the interfacial tension in binary mixtures, imagining an interface of continuously changing concentrations in a direction normal to the interface [46], and using activity coefficients of components in the interfacial region calculated by the UNIQUAC method.

From this literature survey, it is clear that an estimate of the interfacial tension between mixed acid and an aromatic mixture is not possible at present from pure or binary data due to the highly non-ideal behaviour of our mixtures. As a consequence, an empirical correlation fitted to the experimental data seems to be the only solution. Eq. (D4) was chosen and $\phi_{12}$ was used as the fitting parameter. It is necessary to calculate first the surface tension of both phases.
Table 4

Constants for the calculation of the surface tension of mixed acid, $\gamma_{i}$ $\left(\mathrm{N} \mathrm{m}^{-1}\right)$

\begin{tabular}{llll}
\hline Compound & $A$ & $B$ & $C$ \\
\hline $\mathrm{H}_{2} \mathrm{O}$ & $9.77 \times 10^{-2}$ & $-1.626 \times 10^{-5}$ & $-2.35 \times 10^{-7}$ \\
$\mathrm{HNO}_{3}$ & $8.39 \times 10^{-2}$ & $-1.446 \times 10^{-4}$ & 0.0 \\
$\mathrm{H}_{2} \mathrm{SO}_{4}$ & $7.81 \times 10^{-2}$ & $-7.846 \times 10^{-5}$ & 0.0 \\
\hline
\end{tabular}

\section{Mixed acid surface tension}

The surface tension of the mixed acid was calculated using experimental data from pure water and solutions of nitric and sulphuric acid at different concentrations and temperatures as [47]

$$
\begin{aligned}
\gamma_{\mathrm{L} 2}= & \sum_{i=1}^{3} x_{i} \gamma_{i}+\frac{a_{1} x_{\mathrm{W}} x_{\mathrm{N}}}{2 R T}\left(\gamma_{\mathrm{W}}-\gamma_{\mathrm{N}}\right)^{2} \\
& +\frac{a_{2} x_{\mathrm{W}} x_{\mathrm{S}}}{2 R T}\left(\gamma_{\mathrm{W}}-\gamma_{\mathrm{S}}\right)^{2}
\end{aligned}
$$

where $a_{1}=1.64 \times 10^{5}$ and $a_{2}=7.14 \times 10^{5}$ respectively. $x_{i}$ and $\gamma_{i}$ refer to the mass fraction and surface tension of the $i$ th compound respectively. The surface tension was calculated as

$\gamma_{i}\left(\mathrm{Nm}^{-1}\right)=A+B T+C T^{2}$

The constants $A, B$ and $C$ are listed in Table 4. Fig. 12 shows the comparison between the experimental and calculated surface tensions for nitric acid solutions using Eq. (D5).

\section{Aromatic phase surface tension}

The surface tension of the organic phase was calculated using the Physical Properties Data Service (PPDS, Institute of Chemical Engineers, Rugby, UK) and data from Badachhape et al. [48] as

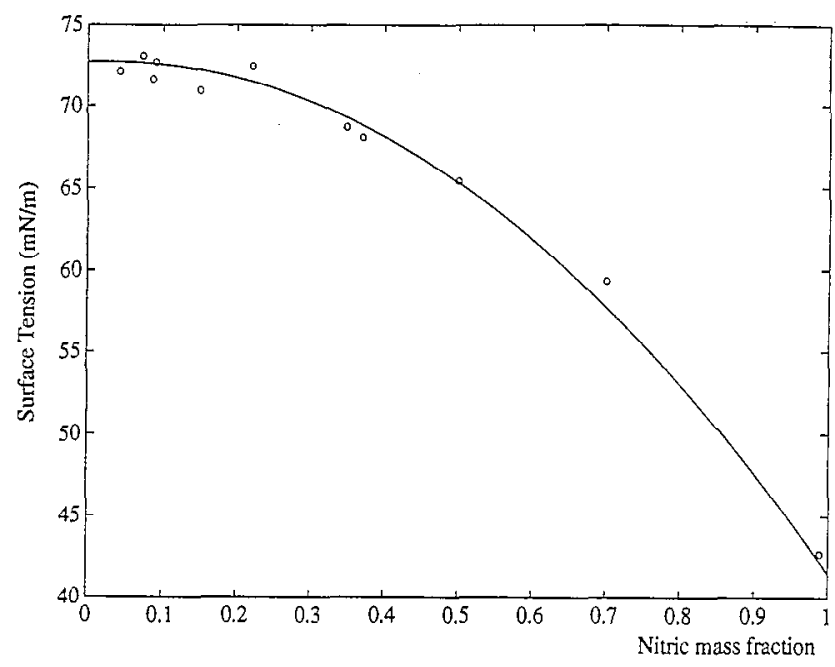

Fig. 12. Experimental (see Perry and Chilton [47]) and correlated surface tension for water-nitric acid mixtures. 
Table 5

Constants for the calculation of the surface tension of organic mixtures, $\gamma_{i}\left(\mathrm{~N} \mathrm{~m}^{-1}\right)$

\begin{tabular}{lll}
\hline Compound & $A$ & $B$ \\
\hline Benzene & $6.65 \times 10^{-2}$ & $-1.283 \times 10^{-4}$ \\
Nitrobenzene & $7.91 \times 10^{-2}$ & $-1.193 \times 10^{-4}$ \\
Toluene & $6.36 \times 10^{-2}$ & $-1.197 \times 10^{-4}$ \\
o-MNT & $7.75 \times 10^{-2}$ & $-1.217 \times 10^{-4}$ \\
$m-\mathrm{MNT}$ & $7.52 \times 10^{-2}$ & $-1.153 \times 10^{-4}$ \\
$p$-MNT & $6.91 \times 10^{-2}$ & $-9.815 \times 10^{-5}$ \\
Chlorobenzene & $6.80 \times 10^{-2}$ & $-1.177 \times 10^{-4}$ \\
o-MNC & $7.98 \times 10^{-2}$ & $-1.163 \times 10^{-4}$ \\
$m$-MNC & $8.84 \times 10^{-2}$ & $-1.418 \times 10^{-4}$ \\
$p$-MNC & $7.44 \times 10^{-2}$ & $-1.045 \times 10^{-4}$ \\
\hline
\end{tabular}

$\gamma_{\mathrm{L} 1}=\sum_{i} x_{i} \gamma_{i}$

where $x_{i}$ and $y_{i}$ refer to the mass fraction and surface tension of the $i$ th compound respectively. The surface tension was calculated as

$\gamma_{i}\left(\mathrm{~N} \mathrm{~m}^{-1}\right)=A+B T$

The constants $A$ and $B$ are listed in Table 5 .

The calculated values deviated by less than $5 \%$ (see Table 6) from the experimentally determined surface tensions of mixtures of toluene and mononitrotoluenes.

\section{Interfacial tension between organic and acid phases}

The value of $\Phi_{12}$ was obtained from the data given by Good and Elbing [44] (see Table 7). The variation of $\Phi_{12}$ during the reaction was determined using the following correlation

$$
\Phi_{12}=x_{\mathrm{ArH}} \Phi_{\mathrm{ArH}}+x_{\mathrm{ArNO}_{2}} \Phi_{\mathrm{ArNO}_{2}}
$$

where $x_{\mathrm{ArH}}$ and $x_{\mathrm{ArNO}_{2}}$ refer to the mass fractions of the aromatic compound being nitrated and the nitration products respectively. Fig. 13 shows the experimental and calculated interfacial tensions using Eq. (D9).
Table 7

Values of $\Phi_{\text {ArH }}$ used in Eq. (D9)

\begin{tabular}{ll}
\hline Compound & $\Phi_{\text {ArH }}$ \\
\hline Benzene & 0.739 \\
Nitrobenzene & 0.805 \\
Toluene & 0.737 \\
MNTs & 0.868 \\
Chlorobenzene & 0.697 \\
MNCs & 0.868 \\
\hline
\end{tabular}

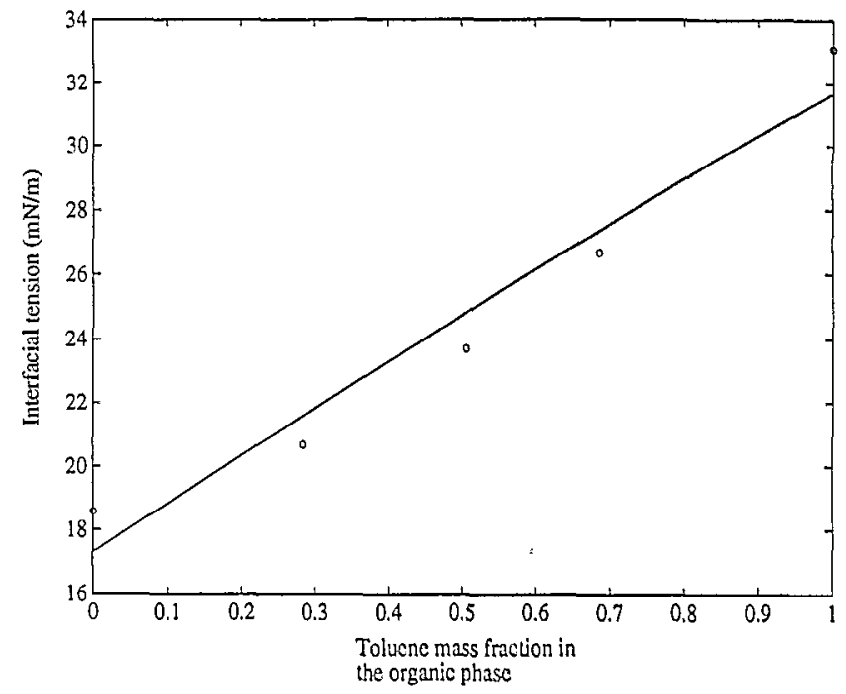

Fig. 13. Experimental (see Giles et al. [49]) vs. calculated interfacial tensions of sulphuric acid and water and mixtures of tolucne and 0.MNT.

\section{References}

[1] K. Schofield, Aromatic Nitration, Cambridge University Press, Cambridge, 1980.

[2] J.M. Zaldivar, E. Molga, M.A. Alós, H. Hernández and K.R. Westerterp, Aromatic nitrations by mixed acid. Slow liquid-liquid reactions, submitted for publication.

[3] K.R. Westerterp, W.P.M. van Swaaij and A.A.C.M. Beenackers, Chemical Reactor Design and Operation, Wiley, Chichester, 1984.

Table 6

Experimental and calculated surface tensions $\left(\mathrm{mN} \mathrm{m}^{-1}\right)$ for organic mixtures at different temperatures

\begin{tabular}{|c|c|c|c|c|c|c|c|c|}
\hline \multirow{2}{*}{$\begin{array}{l}\text { Organic phase } \\
\text { composition (wt. } \% \text { ) }\end{array}$} & \multicolumn{2}{|c|}{$288.2 \mathrm{~K}$} & \multicolumn{2}{|c|}{$298.2 \mathrm{~K}$} & \multicolumn{2}{|c|}{$308.2 \mathrm{~K}$} & \multicolumn{2}{|c|}{$318.2 \mathrm{~K}$} \\
\hline & Exp. & Calc. & Exp. & Calc & Exp. & Calc. & Exp. & Calc. \\
\hline $\begin{array}{l}59 \% \text { o-MNT, } 4 \% m \text {-MNT, } \\
37 \% \text {-MNT } \\
20 \% \text { toluene, } 80 \% \text { MNTs }\end{array}$ & 43.0 & 41.8 & 42.2 & 40.7 & 41.3 & 39.5 & 40.7 & 38.4 \\
\hline above composition & 40.4 & 39.2 & 39.3 & 38.1 & 38.1 & 37.0 & 37.0 & 35.8 \\
\hline
\end{tabular}


[4] J. Villermaux, Drop break-up and coalescence. Micromixing effects in liquid-liquid reactors, in A.E. Rodriguez, J.M. Calo and N.H. Sweed (eds.), Multiphase Chemical Reactors VI. Fundamentals, Sijthoff et Noordhoff, Alphen aan den Rijn, 1981, 285-362.

[5] E. Molga, J.M. Zaldivar and H. Hernández, Effective interfacial area in semibatch liquid-liquid stirred tank reactors, Technical Note 1.94.99, Joint Research Center-Ispra Site, 1994.

[6] F.B. Sprow, Distribution of drop sizes produced in turbulent liquid-liquid dispersions, Chem. Eng. Sci., 22 (1967) 435-442.

[7] S. Kumar, R. Kumar and K.S. Gandhi, A new model for coalescence efficiency of drops in stirred dispersion, Chem. Eng. Sci., 48 (1993) 2025-2038.

[8] A.N. Kolmogorov, The break-up of droplets in a turbulent stream, Dokl. Akad. Nauk, 66 (1949) 825-828.

[9] C.A. Coulaloglou and L.L. Tavlarides, Drop size distribution and coalescence frequencies of liquid-liquid dispersions in flow vessels, AIChE J., 22 (1976) 289-297.

[10] L.L. Tavlarides and M. Stamatoudis, The analysis of interphase reactions and mass transfer in liquid-liquid dispersions, in T.B. Drew, G.R. Cokelet, J.W. Hoopes, Jr. and T. Vermeulen (eds.), Advances in Chemical Engineering, Vol. 11, Academic Press, New York, 1981.

[11] B.W. Brooks and H.N. Richmond, Phase inversion in non-ionic surfactant-oil-water systems II. Drop size studies in catastrophic inversion with turbulent mixing, Chem. Eng. Sci., 49 (1994) 1065-1075.

[12] M.A. Delichatsios and R.F. Probstein, The effect of coalescence on the average drop size in liquid-liquid dispersions, Ind. Eng. Chem. Fundam., 15 (1976) 134-137.

[13] P.H. Calderbank, Physical rate process in industrial fermenters, I. The interfacial area in gas-liquid contacting with mechanical agitation, Trans. Inst. Chem. Eng., 36 (1958) 43-48.

[14] K.R. Westerterp, L.L. van Dierendonck and J. de Kraa, Interfacial area in agitated gas-liquid contactors, Chem. Eng. Sci., 18 (1963) 147-176.

[15] D.S. Sankholkar and M.M. Sharma, A new system for the measurements of effective interfacial area in agitated liquid-liquid contactors by the chemical method, Chem. Eng. Sci., 28 (1973) 2089-2092.

[16] S. Okuf, E.S. Perez de Ortiz and H. Sawistowski, Scale-up of liquid-liquid dispersion in stirred tanks, Can. J. Eng., 68 (1990) $400-406$.

[17] G.S. Laddha and T.E. Degaleesan, Transport Phenomena in Liquid Extraction, McGraw-Hill, New Delhi, 1976.

[18] R. Kronig and J.C. Brink, On the theory of extractions from falling droplets, Appl. Sci. Res. A, 2 (1960) 142-154.

[19] R.J. Brunson and R.M. Wellek, Mass transfer inside liquid droplets and gas bubbles accompanied by a second-order chemical reaction, AIChE J., 17 (1971) 1123-1130.

[20] M. Steensma and K.R. Westerterp, Thermally safe operation of a cooled semi-batch reactor. Slow liquid-liquid reactions, Chem. Eng. Sci., 43 (1988) 2125-2130.

[21] D. Bonvin and U. Saner, On line procedures for supervising the operation of batch reactors, Comput. Chem. Eng., 12 (1988) $371-376$.

[22] J.M. Zaldivar, H. Hernández and C. Barcons, Development of a numerical simulator for a reaction calorimeter. FISIM, $\mathrm{RCl}$ version, Technical Note I.90.109, Joint Research Center-Ispra Site, 1990.

[23] J.M. Zaldivar, H. Hernández, C. Barcons and R. Nomen, Heat effects due to dilution during aromatic nitrations by mixed acid in batch conditions, J. Therm. Anal., 38 (1992) 2575-2582.

[24] E. Molga, C. Barcons and J.M. Zaldivar, Mononitration of toluene and quantitative determination of the isomer distribution by gas chromatography, Afinidad, 50 (1993) 15-20.

[25] H. Hernández, J.M. Laldivar and C. Barcons, Development of a mathematical model and a numerical simulator for the analysis and optimization of batch reactors, Comput. Chem. Eng., I7S (1993) 45-50.

[26] J.M. Zaldivar, M.A. Alós, E. Molga, H. Hernández and K.R. Westerterp, The effect of phase inversion during aromatic nitrations, submitted for publication.

[27] J.B. Fernandez and M.M. Sharma, Effective interfacial area in agitated liquid-liquid contactors, Chem. Eng. Sci., 22 (1967) $1267-1282$.

[28] M. Steensma and K.R. Westerterp, Thermally safe operation of a semibatch reactor for liquid-liquid reactions. Fast reactions, Chem. Eng. Technol, 14 (1991) 367-375.

[29] C. Hanson (ed.), Recent Advances in Liquid-Liquid Extraction, Pergamon, Oxford, 1971.

[30] P.H. Calderbank and M.B. Moo-Young, The continuous phase heat and mass-transfer properties of dispersions, Chem. Eng. Sci., 16 (1961) 39-54.

[31] V.W. Uhl and J.B. Gray (ed.), Mixing: Theory and Practice, Vol. 1, Academic Press, New York, 1966.

[32] M. De Santiago and P. Trambouze, Applicabilité de la méthode chimique de measure de l'aire interfaciale, Chem. Eng. Sci., 26 (1971) $1803-1815$

[33] Bourne et al.

[34] J.W. Chapman, P.R. Cox and A.N. Strachan, Two phase nitration of toluene III, Chem. Eng. Sci., 29 (1974) 1247-1251.

[35] R.E. Treybal, Liquid Extraction, McGraw-Hill, New York, 2nd edn., 1963.

[36] A.I. Johnson and A.E. Hamiclce, Mass transfer inside drops, AIChE J., 6 (1960) 145-149.

[37] A.E. Handlos and T. Baron, Mass and heat transfer from drops in liquid-liquid extraction, AIChE J., 3 (1957) 127-136.

[38] R.M. Wellek and A.H.P. Skelland, Extraction with single turbulent droplets, AIChE J., 11 (1965) 557-560.

[39] R.R. Schroeder and R.C. Kintner, Oscillations of drops falling in a liquid field, AIChE J., 11 (1965) 5-8.

[40] J.A. Wesselingh, The velocity of particles, drops and bubbles, Chem. Eng. Process, 21 (1987) 9-14.

[41] S. Hu and R.C. Kintner, The fall of single liquid drops through water, AIChE J., 1 (1955) 42-48.

[42] H.M. Backes, J.J.M.E. Bender and G. Maurer, Interfacial tensions in binary and ternary liquid-liquid systems, Chem. Eng. Sci., 45 (1990) 275-286.

[43] D.J. Donahue and F.E. Bartell, The boundary tension at waterorganic liquid interfaces, J. Phys. Chem., 56 (1952) 480-484.

[44] R.J. Good and E. Elbing, Generalization of theory for estimation of interfacial energies, Ind. Eng. Chem., 62 (1970) 54-78.

[45] B. Li and J. Fu, Prediction of interfacial tension of binary liquid mixtures from mutual solubility by the UNIQUAC method, Chem. Eng. Sci., 44 (1989) 1519-1527.

[46] M. Kahlweit, Calculation of the interfacial tension between two phases of a binary system, Z. Phys. Chem., 34 (1962) 163-181.

[47] R.H. Perry and C.H. Chilton, Chemical Engineers' Handbook, McGraw-Hill, New York, 6th edn., 1984.

[48] R.B. Badachhape, M.K. Gharpurey and A.B. Biswas, Density and surface tension of phenol, (mono, di-, and tri-) chlorophenols, salol and ( 0 - and $m-$ ) chloronitrobenzenes, J. Chem. Eng. Data, 10 (1965) 143-145.

[49] J.W. Giles, C. Hanson and J.G. Marsland, Drop size distribution in agitated liquid-liquid systems with simultaneous interface mass transfer and chemical reaction, Proc. Int. Solv. Extr. Conference, Society of Chemical Industries, 1971, pp. 94-111.

[50] P.H. Calderbank, in V.W. Uhl and J.B. Gray (eds.), Mixing Theory and Practice, Academic Press, New York, 1967. 